\title{
Local cooling for traumatic spinal cord injury: outcomes in 20 patients and review of the literature
}

\author{
Clinical article
}

\author{
Robert R. Hansebout, M.D., M.Sc., ${ }^{1}$ \\ and Christopher R. Hansebout, M.B.B.S., B.Sc., M.Sc. ${ }^{2}$ \\ ${ }^{1}$ Department of Surgery, Division of Neurosurgery, McMaster University, Hamilton, Ontario, Canada; and \\ ${ }^{2}$ Faculty of Medicine, University of Queensland, Brisbane, Australia
}

\begin{abstract}
Object. In this prospective study, the authors offered protocol-selected patients a combination of parenteral steroids, decompression surgery, and localized cooling to preserve viable spinal cord tissue and enhance functional recovery.

Methods. After acquiring informed consent, the authors offered this regimen with localized deep cord cooling (dural temperature $6^{\circ} \mathrm{C}$ ) to 20 patients with a neurologically complete spinal cord injury to begin within 8 hours of injury. After decompression, the cord was locally cooled through the intact dura using a suspended extradural saddle at the site of injury for up to 4 hours, during which time spinal fusion was performed. Sensation and motor function were evaluated directly after the injury and again over a year later. The patients were evaluated using the 2011 amendment to the American Spinal Injury Association (ASIA) Impairment Scale.

Results. Eighty percent of the 20 patients (12 with cervical and 4 thoracic injuries) with an initial neurologically complete cord injury had some recovery of sensory or motor function. All patients initially had ASIA Grade A impairment. Of 14 patients with quadriplegia, 5 remained ASIA Grade A, 5 improved to ASIA Grade B, 3 to ASIA Grade C, and 1 to ASIA Grade D. The remaining 6 patients had suffered a thoracic spinal cord injury, and of these 2 remained ASIA Grade A, 1 recovered to ASIA Grade B, 2 to ASIA Grade C, and 1 ASIA Grade D. All considered, of 20 patients, $35 \%$ remained ASIA Grade A, 30\% improved to ASIA Grade B, and 25\% to ASIA Grade C. Impairment in $2(10 \%)$ of 20 patients improved to ASIA Grade D. The mean improvement in neurological level of injury in all patients was 1.05 , the mean improvement in motor level was 1.7 , and the mean improvement in sensory level was 2.8. Two patients recovered the ability to walk, 2 could extend their legs, 5 could sense bladder fullness, and 3 had partial ability to void voluntarily. Four males recovered subnormal ability to have voluntary erection sufficient for limited sexual activity.

Conclusions. The authors present here results of 20 patients with neurologically complete spinal cord injury treated with a combination of surgical decompression, glucocorticoid administration, and regional hypothermia. These patients experienced a better recovery than might have been expected had traditional forms of treatment been used. The benefit of steroid treatment for cord injury has been debated in the last decade, but the authors feel that research into the effects of cord cooling should be expanded. Given that the optimal neuroprotective temperature after acute trauma has not yet been defined, and may well be below that which is considered safely approachable through systemic cooling, methods that allow for the early attainment of such a temperature locally should be further explored. The results are encouraging enough to suggest the undertaking of controlled clinical trials of treatment using localized spinal cord cooling, where such treatment can be instituted within hours following injury.
\end{abstract} (http://thejns.org/doi/abs/10.3171/2014.2.SPINE13318)

\section{KeY WordS • local hypothermia - regional hypothermia • steroid treatment • spinal cord cooling • $\quad$ spinal cord injury • spinal decompression • trauma}

$\mathrm{S}$ PINAL cord injury (SCI) can be devastating to the victim's quality of life. While modern treatment of SCI has lessened its associated morbidity and mortality, there remains place for improvement of outcomes. ${ }^{9,44}$ In severe SCI, the primary injury forces destroy or damage neural tissue, causing sudden loss of neurological func-

Abbreviations used in this paper: ASIA = American Spinal Injury Association; ISNCSCI = International Standards for the Neurological Classification of Spinal Cord Injury; NLI = neurological level of injury; $\mathrm{SCI}=$ spinal cord injury. tion below the lesion but often leaving strands of cord intact. A secondary autodestructive process ${ }^{8}$ ensues with hemorrhage and increasing edema, leading to infarction of cord tissues. This, along with other processes, ${ }^{56,77}$ aggravates spinal cord damage and further impairs neural transmission. Researchers have felt that if this secondary damage could be arrested, the chances of functional neurological recovery could be enhanced..$^{82}$

The following report describes the treatment and follows, over many years, the recovery of 20 patients who presented with a neurologically complete SCI. It includes 
extended follow-up of 10 patients who had been briefly described and followed up for a short time in a preliminary report ${ }^{47}$ and includes an additional 10 patients.

\section{Methods}

\section{Background}

Steroids After SCI. At the time this study was started there was enthusiasm in the literature for the beneficial effects of parenteral steroids following SCI in animals..$^{714,23,33,41,45,67}$ More recent human trials ${ }^{18,19,22}$ fortified this notion. Other investigators ${ }^{51,52}$ did not agree or felt the evidence supporting use of steroids in SCI was weak. Steroid administration, nonetheless, was considered a treatment of choice for human cord injury and, at the time of our study, extending from 1977 through 1987, steroids were widely used. ${ }^{83}$ The dosing regimen of dexamethasone used here was developed using information from earlier laboratory studies, ${ }^{46,66}$ which showed that its administration preserved intracellular potassium, reduced tissue damage, and was correlated with better neurological recovery. Based on previous laboratory studies, we administered steroids to our patients for 11 days with gradual tapering to cessation on the 18th day. ${ }^{45}$

Cooling After SCI. There has been considerable interest in cooling the injured spinal cord to enhance recovery of neurological function. ${ }^{56}$ Salutary effects of cooling the traumatized spinal cord in animals were shown by a number of early investigators. ${ }^{4-6,13,15,23,31,57,60,61,75,76,84,86}$ In a literature review, ${ }^{43}$ we found that local spinal cord cooling had been used in 70 patients with a neurologically complete SCI at 11 centers by 1982 . Combined steroid and hypothermia therapy was administered to $51 \%$ of patients. The rate of neurological improvement in some form was $54 \%$, the ambulation rate was $14 \%$, and the 1 -year mortality rate was $13 \%$.

We felt that spinal cord cooling could be beneficial in the treatment of the injured spinal cord but that the optimal cooling temperature might be lower than what is feasible through systemic hypothermia. We elected to use local hypothermia, allowing for more profound selective cooling of injured tissue while avoiding potential complications of deep general hypothermia. We opted for localized extradural cord hypothermia using equipment developed in collaboration with the National Research Council of Canada. ${ }^{78}$ Prior to use in humans, we determined conditions for optimal cooling in the laboratory. In a study of delayed cooling, we showed that the best motor recovery occurred in dogs whose traumatized spinal cords were cooled for a duration of 4 hours instead of 1 hour or 18 hours. ${ }^{86}$ We also showed that after severe cord trauma combining steroid agents and local spinal cord cooling at a central cord temperature of around $17^{\circ} \mathrm{C}$ produced better neurological motor recovery than conservative treatment or the single use of either. ${ }^{45}$

A 2008 literature review noted that "local hypothermia was actively studied in the 1970s in human acute traumatic SCI, but no case series of this intervention has been published since 1984." ${ }^{62}$ As this referred to our 1984 paper we felt it appropriate to share our long-term experience.
The long follow-up is relevant because meaningful recovery after SCI may occur years after the injurious event. ${ }^{70}$

\section{Equipment}

We began using spinal cord cooling in patients in 1977. The active study lasted 10 years, and the mean follow-up period was 4.9 years (range $14-153$ months [Table 1]). The original cooling apparatus was large and cumbersome. A light, portable unit that could be deployed in various hospitals was later built (Fig. 1). This machine cooled a probe inserted into a heat exchanger. A rotary pump propelled normal saline through the heat exchanger at $3^{\circ} \mathrm{C}$, then through a muffler, and finally into a soft, pliable Silastic saddle (Fig. 2) containing multiple microscopic channels; this suspended saddle rested lightly upon the unopened dura and cooled it to $6^{\circ} \mathrm{C}$. A thermocouple measured the dural temperature. Saline was then returned from the cooling saddle to the reservoir, completing the closed circuit. In our earlier experiments on dogs, the central cord temperature in these conditions reached $17^{\circ} \mathrm{C}$ in $2-3$ minutes. ${ }^{78} \mathrm{In}$ the same experiments it returned to normal temperature in 10 minutes when cooling ceased. The cooling system is diagrammatically represented in Fig. 3.

\section{Protocol}

A protocol was set up at hospitals in our catchment area in Canada to inform the senior author when a patient with a severe SCI was to be transported to the trauma hospital. It was suggested to the referring physician that a loading dose of $20 \mathrm{mg}$ of dexamethasone be given intramuscularly before rapid transfer. The senior author examined patients to determine neurological completeness and to gauge the patient's suitability for inclusion in the series. Eligibility criteria required that patients be alert and cooperative; between the ages of 16 and 65 years; and have no motor or sensory function below the level of cord injury, no perianal sensation, and no anal sphincter contraction. Cooling was offered only to patients with a clinically complete cord injury. It is believed that a person with a neurologically "complete" SCI rarely recovers function below the lesioned level when conventional treatment is applied. ${ }^{37}$ We made a diagnosis of a "complete spinal cord injury" based on the finding of completely absent neurological function. Because the patients in our series had no bulbocavernosus reflex, an absolute diagnosis of complete injury could not be made due to the possibility of spinal shock; ${ }^{30}$ allowing time for recovery of the reflex, however, would have meant delaying treatment to the point where it would have lost substantial efficacy. ${ }^{83}$ We aimed to begin cooling the cord within 8 hours of injury. Individuals fitting the selection criteria constituted less than $3 \%$ of patients with a severe SCI seen in our trauma hospital, and consequently the series took 10 years to acquire the 20 patients.

The nature of the procedure was explained and full informed consent obtained. During investigation, the patient's blood pressure and blood gases were monitored and maintained within an acceptable range. In cases of cervical injuries, halo traction was applied. The patient's shoulders were pulled down to improve visualization on radiographs of the cervical vertebrae. If necessary, closed reduction 


\section{R. R. Hansebout and C. R. Hansebout}

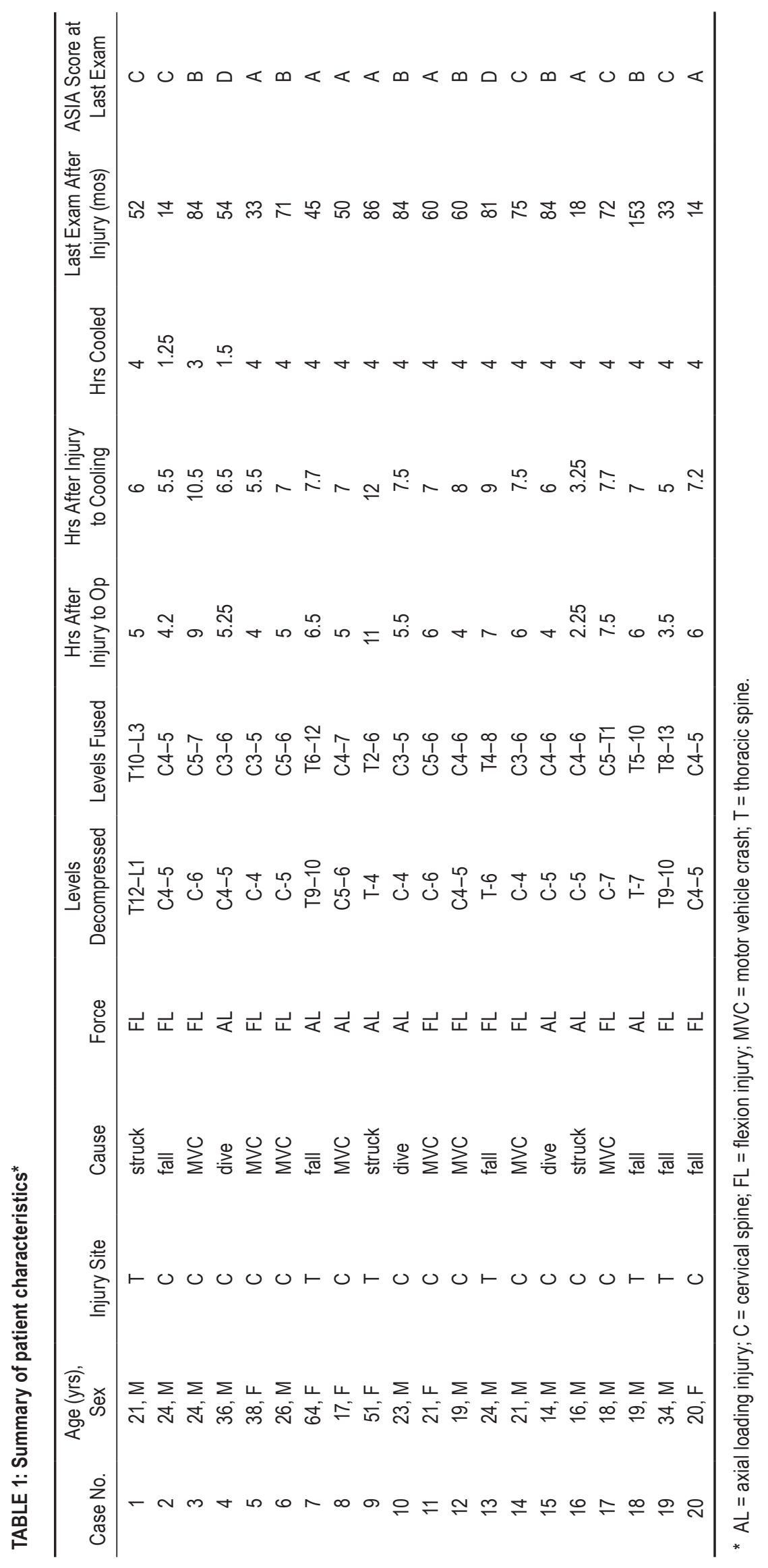




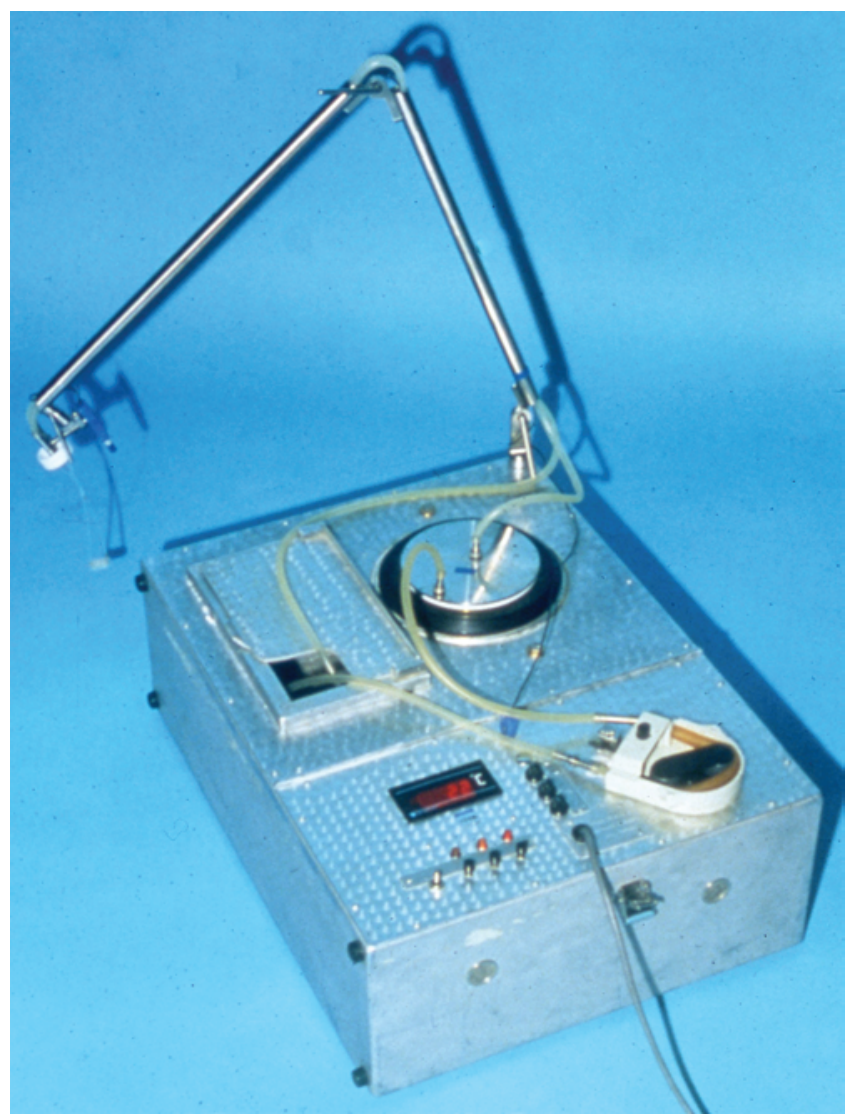

Fig. 1. Our first prototype of a portable cord cooling apparatus for humans was developed in collaboration with the National Research Council of Canada. The arm mounted on a universal joint can be variably positioned to hold the cooling saddle suspended lightly over the dura. The cooling saddle is shown dangling from the far end of the arm. This system can be deployed for rapid use in various hospitals.

was tried during traction under radiographic control. In the interest of time, plain radiographs (3 high-quality views) were the only images taken at the injury site since the dura and occasionally the cord through a disrupted dura would be visualized at surgery. An anterior or posterior operative approach was decided on in collaboration with an orthopedic surgeon. In cases of cervical trauma, the patient remained in traction during surgery.

Following exposure, any necessary vertebral alignment was completed, and the spinal cord was decompressed. The suspended cooling saddle (Fig. 2) was then placed lightly against the dura. Transdural cord cooling was continued for up to 4 hours at a dural temperature of $6^{\circ} \mathrm{C}$ (Fig. 3). Fusion was often performed by the orthopedic surgeon during the cooling stage. On cessation of cooling, the dura and cord were allowed to warm spontaneously. Routine postoperative care was conducted, including intermittent bladder catheterization and a strong emphasis on chest physiotherapy. Dexamethasone was given according to a dosing regimen developed from our earlier laboratory studies: ${ }^{46,66} 6 \mathrm{mg}$ every 6 hours was given for 11 days and then tapered gradually until discontinuation on the 18th day after injury.

The patients were seen and examined by the senior author and a spinal cord team during hospitalization and

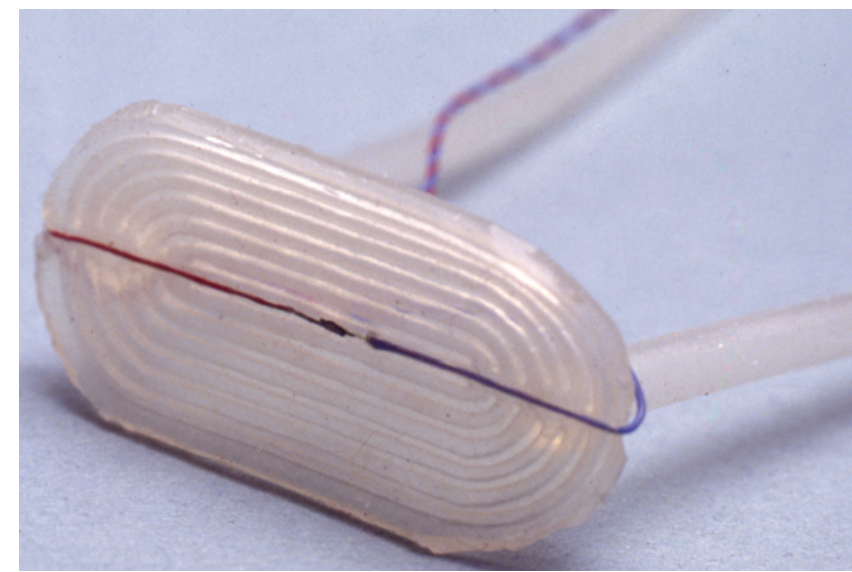

FIG. 2. The epidural cooling saddle. There are various models contoured to fit the dura from an anterior or posterior approach in the cervi$\mathrm{cal}$ or thoracic regions. A thermocouple measures the dural temperature so the apparatus keeps it at a constant $6^{\circ} \mathrm{C}$ for several hours.

later in clinics. Information was recorded and included any additional injury or complication. Complications were further classified as "early," if they occurred within the first month after injury, or "late," if they occurred later. Neurological evaluation of motor and sensory recovery was performed by the senior author at intervals during the follow-up, which varied from 14 to 153 months and was, on average, 4.9 years after the injury (Table 1 ).

This prospective study was begun in 1977 before publication of the American Spinal Injury Association (ASIA) Impairment Scale. We had used our own 5-point scale to measure sensory and motor function initially and later for determination of any improvement. Our motor power grades resembled the usual grades for strength and are comparable to those found in the International Standards for the Neurological Classification of Spinal Cord Injury (ISNCSCI) and used to classify patients according to the ASIA Impairment Scale. Our sensory scale had 6 grades, corresponding to 0 (no sensation), 1 (crude pressure), 2 (touch sensation), 3 (pain and temperature or dorsal column sensation), 4 (subnormal pain, temperature and dorsal column sensation), or 5 (normal sensation). In view of the popularity of the ASIA grading scale, we matched our data to the 2011 modifications of the ISNCSCI ${ }^{59}$ Our Grade 0 remained the same; we combined our Grades 1-4 and converted them to Grade 1 on the ISNCSCI sensory scale. Our Grade 5 was converted into Grade 2 sensation on the ISNCSCI sensory scale. Determination of motor level, sensory level, neurological level of injury (NLI), and zone of partial preservation were as per Kirshblum et al. ${ }^{59}$ Briefly, to quantitate the degree of neurological recovery, particularly of the upper extremities, we determined the single NLI. The NLI refers to the most caudal segment of the spinal cord with normal (Grade 2/2) sensory and antigravity (Grade 3/5) motor function, provided that there is normal sensory and motor function rostrally. This may differ between left and right sides of the body. Therefore, 4 separate levels are possible: a right sensory level; left sensory level; right motor level; and a left motor level. The single NLI is the most rostral of these 4 levels. We determined the motor level for each side, which indicates ASIA Grade 


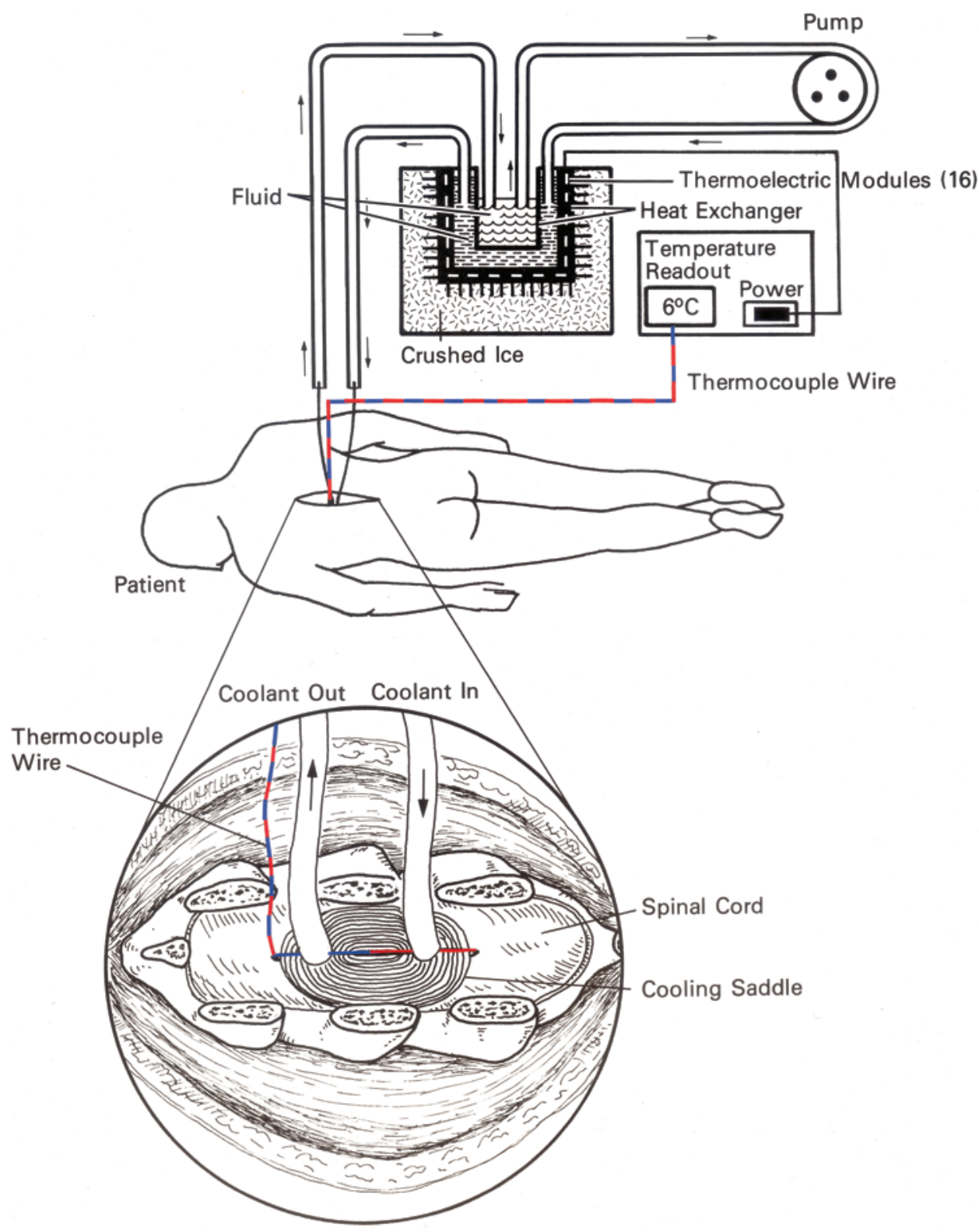

FIG. 3. Schematic drawing depicting dural cooling in the thoracic region when a posterior approach is being used. Water is propelled by a pump through a heat exchanger, which in turn cools the water in a closed, sterile circuit. This process cools the human spinal cord cooling saddle. The lower portion of the drawing shows a magnified view of the cooling saddle placed lightly on the dura. It is possible to perform a spinal fusion around the placement of the cooling unit while cooling is underway. Copyright Robert Hansebout. Published with permission.

3 motor power muscle function provided there is normal (Grade 5/5) motor power at the rostral level. A higher score can reflect improvement in function of the extremities. In addition, we also determined the sensory level, the most caudal neurological level with ASIA sensory Grade 2 (normal sensation). Return of sensation to normal can provide protection from skin breakdown, detect bladder fullness, general sensation, sexual sensation, and allow better balance and proprioception. These measurements were determined in the acute stage. We later compared these findings with those determined on follow-up.

The ability of patients to complete various activities of daily living and enjoy some degree of mobility was recorded. Should they have had sufficient function to perform these tasks, as well as to have attested to their ability to live independently, they were considered to be self-sufficient. We also inquired about bowel and bladder control as well as sexual function.

\section{Results}

Three patients underwent treatment but were not included in the series. One of these had a severe head injury and died within 2 weeks. A second patient had an incomplete SCI but was treated very early on. He is the only patient with an incomplete SCI who underwent decompres- 
sion, cooling, and steroid therapy; he made a remarkable and rapid recovery from a severe, though incomplete, cord injury. A third patient did have a neurologically complete SCI but another surgeon treated him. The patient recovered quite well, but recorded data were incomplete. These three were all the individuals excluded from the series.

Four of our 20 patients (Table 1) received treatment at the Montreal Neurological Hospital; the remainder were treated at the Hamilton General Hospital. There were 14 males and 6 females. Patients were followed up for at least 1 year. All 20 patients presented with complete neurological SCI. Of these, 14 had cervical injuries while 6 had thoracic injuries. Motor vehicle crashes caused 8 injuries, 6 were caused by falls, 3 resulted from diving, and 3 were caused by a forceful blow. A flexion force to the spine caused injury in 12 cases, while axial loading caused injury in 8 . The average age of the males in the series was 22.8 years, and the average age of the females in the series was 35.1 years, reflecting the presence of 3 women aged 64, 51, and 38 years. Some individuals were followed up for as long as 12 years; the average followup period was just less than 5 years. Eight $(40 \%)$ of the patients had sustained multiple injuries, and $2(10 \%)$ had suffered a significant head injury (Table 2).

All patients received decompressive surgery, parenteral steroids, and local spinal cord cooling. Table 3 shows the average time after injury for steroid administration, the time between injury to the start of cooling, and total duration of cooling. As dexamethasone was often administered at collector hospitals, it was delivered relatively early (mean 5.6 hours postinjury). Due to patient transfer, medical stabilization, and surgical exposure of the dura, cooling was begun on average 7.1 hours postinjury. We aimed for the duration of cooling to be 4 hours. The average duration of cooling was 3.7 hours.

At the onset of cooling, the dura often showed reddish coloration due to hemorrhage from the underlying injured cord and the dura was tightly stretched over the cord (Fig. 4). After several hours of cooling at $6^{\circ} \mathrm{C}$, the dura was lighter in coloration and appeared to be less tightly stretched over the cord (Fig. 5), although dural pulsations were not observed.

A majority of patients required additional surgery, often tracheostomy. Rarely required was decubitus ulcer debridement or pyloroplasty. Early complications were pulmonary related, and included atelectasis and pneumonia, followed by decubitus ulceration, spinal instability, gastrointestinal bleeding, depression, and deep vein thrombosis (Table 4). Late-onset complications were decubitus ulceration, urinary tract infection, bladder calculi, and pain (Table 4).

Impairment in all patients was initially categorized

TABLE 2: Factors having a deleterious effect on recovery

\begin{tabular}{lc}
\hline \multicolumn{1}{c}{ Factor } & No. of Patients $(\%)$ \\
\hline head injury & $2(10)$ \\
multiple injuries & $8(40)$ \\
early complications & $16(80)$ \\
late complications & $18(90)$ \\
\hline
\end{tabular}

TABLE 3: Mean timing of various interventions

\begin{tabular}{cc}
\hline Intervention & Time in Hrs \\
\hline time to steroid administration & 5.6 \\
time to cooling start & 7.1 \\
duration of cord cooling & 3.7 \\
\hline
\end{tabular}

as ASIA Grade A. Final follow-up ASIA grades are summarized in Table 5. Impairment in 7 patients $(35 \%)$ remained ASIA Grade A, improved in $6(30 \%)$ to Grade $\mathrm{B}$, improved in $5(25 \%)$ to Grade $\mathrm{C}$, and improved in 2 (10\%) to Grade D. Of the 14 patients with cervical injuries, the status of $5(35.7 \%)$ remained ASIA Grade A; it improved in $5(35.7 \%)$ to Grade B, improved in $3(21.4 \%)$ to Grade C, and improved in $1(7.2 \%)$ to Grade D. The remaining 6 patients sustained a complete thoracic cord injury: 2 (33.3\%) remained Grade A, $1(16.7 \%)$ improved to Grade B, 2 (33.3\%) improved to Grade C, and 1 (16.7\%) improved to Grade D.

Improvement in the NLI signifies improvement in sensorimotor function in the patients. Taken as a group, our patients experienced a caudal descent of 21 vertebral segments for a mean of 1.05 segmental levels per patient (Table 6). In the 14 patients with cervical injury, there was caudal improvement in the NLI of 13 vertebral segmental levels, a mean of 0.93 levels per patient. For patients with thoracic injury, there was improvement of 8 segmental levels, a mean of 1.33 levels per patient.

A descent of the motor level signifies improvement in motor function, especially in the extremities (Table 6). We compared our motor level findings after initial injury with those on follow-up to determine improvement in motor function. As a group, there was a caudal migration of the motor level by 28 levels, a mean of 1.7 functional levels per patient. In the patients with cervical injury, 13 levels were recovered for a mean of 0.92 levels per patient. Paraplegic patients with thoracic injuries had a return of 15 levels for a mean of 2.5 levels per patient.

The sensory level is the most caudal dermatome at and rostral to which there is bilaterally normal sensation.

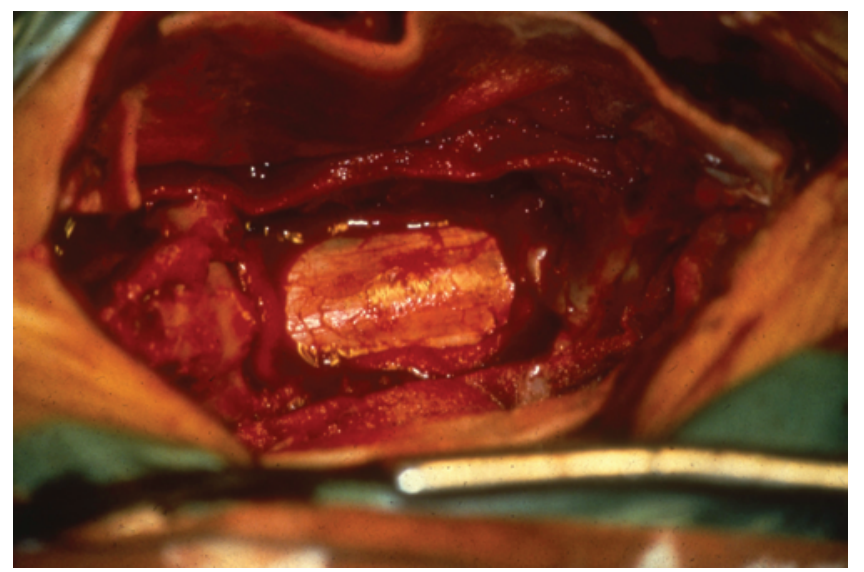

Fig. 4. Case 17. Intraoperative photograph of the exposed dura at C-7 before cord cooling was initiated about 7 hours after injury. Note the bluish discoloration of the distended dura over the injured cord, with a hematoma seen through dura in upper left corner. 


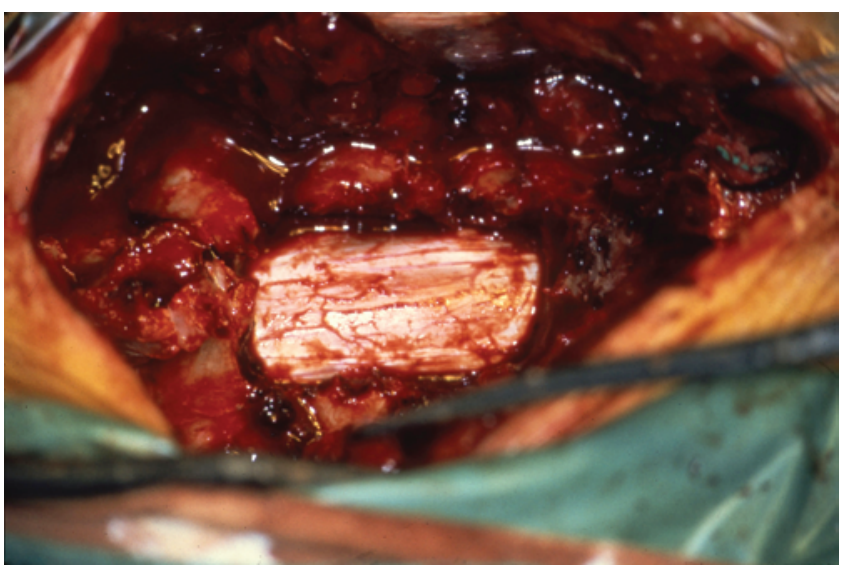

Fig. 5. Case 17. Intraoperative photograph of the exposed dura at C-7 after 4 hours of deep cord cooling. Note that the dura appears more lax, with less bluish discoloration.

Return of sensation to normal can provide protection from skin breakdown, allow the detection of bladder fullness, and provide for sexual sensation. Caudal migration of the sensory level in patients with cervical injury can provide much useful function, especially in the hands. For all 20 patients, there was a caudal migration of the sensory level of 55.5 dermatomal levels for a mean of 2.8 segmental levels per patient. For patients with cervical injury, 43.5

\section{TABLE 4: Summary of complications*}

\begin{tabular}{lc}
\hline \multicolumn{1}{c}{ Complication } & No. of Patients \\
\hline early onset & 9 \\
atelectasis & 7 \\
pneumonia & 6 \\
decubitus ulcers & 5 \\
bone instability & 4 \\
Gl bleeding & 4 \\
depression & 4 \\
deep vein thrombosis & 2 \\
cardiac arrest & 2 \\
increased neural deficit & 2 \\
CSF leak & 2 \\
septicemia & 1 \\
postoperative infection & 1 \\
hydrocephalus & 1 \\
meningitis & 10 \\
late onset & 6 \\
decubitus ulcers & 5 \\
urinary tract infection & 1 \\
bladder stones & 3 \\
pain & 1 \\
respiratory & \\
deep vein thrombosis & \\
spasticity & 2 \\
\hline
\end{tabular}

* An early-onset complication was defined as one occurring within 1 month of injury and a late-onset complication as one occurring more than 1 month after injury. $\mathrm{GI}$ = gastrointestinal.
TABLE 5: Summary of final follow-up ASIA grades*

\begin{tabular}{lccc}
\hline \multirow{2}{*}{ Final } & \multicolumn{3}{c}{ No. of Patients w/ SCl (\%) } \\
\cline { 2 - 4 } Grade & Cervical & Thoracic & All Patients \\
\hline A & $5(35.7)$ & $2(33.3)$ & $7(35)$ \\
B & $5(35.7)$ & $1(16.7)$ & $6(30)$ \\
C & $3(21.4)$ & $2(33.3)$ & $5(25)$ \\
D & $1(7.2)$ & $1(16.7)$ & $2(10)$ \\
total & $14(100)$ & $6(100)$ & $20(100)$ \\
\hline
\end{tabular}

* All patients initially had ASIA Grade A impairment.

levels were recovered, a mean of 3.1 levels per patient. For patients with thoracic injury, 12 levels were recovered, a mean of 2 levels per patient (Table 6).

There are various grades of return of motor and sensory function. So far we have not taken into consideration the total return of all the motor and sensory function in any one patient, including motor function below Grade 3 and sensory function of Grade 1 seen in the zones of partial preservation. To have a picture of motor and sensory improvement in all patients, the total motor scores and total sensory scores were tallied for each patient on admission and on the last follow-up to create a motor index score and sensory index score shown in Table 7. The total motor index score showed a dramatic increase of $174 \%$ in the patients with cervical injury, whereas the increase was only $21 \%$ in the patients with thoracic injury. In all patients, the percentage increase in the motor index score was $63 \%$. Similarly, the sensory index score increased $167 \%$ in patients with cervical injury, reflecting the increased sensation on follow-up compared with admission. There were also increases in the sensory index score by $32 \%$ and $88 \%$ in the thoracic spine-injured patients and all patients, respectively. The mean motor scores for all patients increased from 20.8 to 34 from admission to final follow-up. The mean sensory scores increased from 59.8 to 112.6 at the same time points. In patients with cervical injury, the mean motor scores rose from 8.3 to 22.6 and the mean sensory scores from 35.7 to 95.4 from admission to final follow-up. The mean motor scores for thoracic spine-injured patients rose from 50 to 60.5 , while the mean sensory score rose from 116 to 152.7 from admission to last follow-up, respectively. These figures reflect a considerable return of motor and sensory function.

At the time of final follow-up, $80 \%$ of the patients (12 with cervical and 4 with thoracic injuries), who initially presented with neurologically complete injury, recovered some degree of sensory or motor function; $20 \%$ ( 2 cervical and 2 thoracic) did not. Twelve patients (9 with cervical and 3 with thoracic injuries) recovered some sensorimotor function, while 3 with cervical injury and 1 thoracic injury recovered some sensation only. Two males regained the ability to walk. One, a patient who had sustained a cervical injury, could walk about 25 m unassisted. The other, a patient who had sustained a thoracic injury, regained the ability to walk 4 city blocks using canes. Two male patients with cervical injury could extend their legs against gravity but not enough to ambulate. Five patients could sense bladder fullness, and 3 males 
Local spinal cord cooling for trauma

TABLE 6: Caudal improvement in level of neurological function*

\begin{tabular}{|c|c|c|c|c|c|c|c|}
\hline \multirow[b]{2}{*}{$\begin{array}{l}\text { Level of Spinal } \\
\text { Injury }\end{array}$} & \multicolumn{2}{|c|}{ Neurological Level of Injury } & \multicolumn{2}{|c|}{ Motor Level to Grade $\geq 3$} & \multicolumn{2}{|c|}{ Sensory Level to Grade 2} & \multirow[b]{2}{*}{$\begin{array}{c}\text { Total No } \\
\text { of Pts }\end{array}$} \\
\hline & $\begin{array}{l}\text { Segmental Levels } \\
\text { Recovered }\end{array}$ & $\begin{array}{c}\text { Mean Segmental } \\
\text { Levels/Pt }\end{array}$ & $\begin{array}{l}\text { Segmental Levels } \\
\text { Recovered }\end{array}$ & $\begin{array}{c}\text { Mean Segmental } \\
\text { Levels/Pt }\end{array}$ & $\begin{array}{l}\text { Segmental Levels } \\
\text { Recovered }\end{array}$ & $\begin{array}{c}\text { Mean Segmental } \\
\text { Levels/Pt }\end{array}$ & \\
\hline cervical & 13 & 0.93 & 13 & 0.92 & 43.5 & 3.11 & 14 \\
\hline thoracic & 8 & 1.33 & 15 & 2.5 & 12 & 2 & 6 \\
\hline all & 21 & 1.05 & 28 & 1.73 & 55.5 & 2.77 & 20 \\
\hline
\end{tabular}

* $\mathrm{Pt}=$ patient.

( 2 with cervical injury and 1 with thoracic injury) could initiate voluntary micturition. Of 14 males, 7 recovered a subnormal voluntary erection, in 4 cases sufficient for limited sexual activity. Nine patients were able to attend school or university after the trauma (6 with cervical injury and 3 with thoracic injury) and 6 went back to work ( 3 with cervical injury and 3 with thoracic injury), 5 at professional occupations. Six patients (4 with cervical injury and 2 with thoracic injury) became self-sufficient.

\section{Discussion}

We present follow-up results from the treatment of a series of 20 patients with complete cervical or thoracic SCI who underwent triple therapy with dexamethasone, surgical decompression, and local cord hypothermia. Although it is generally assumed that the majority of recovery has occurred by 2 years after complete SCI, we felt that a longterm follow-up assessment was indicated. Recent reports have indicated that conversion from ASIA Grade A impairment to Grade $\mathrm{C}$ may occur $3-5$ years after the injury. ${ }^{70}$ Accordingly, it is prudent to follow up patients for at least 4-5 years to gauge their ultimate outcome.

This triple-therapy regimen appears to provide patients with substantial benefit compared with traditional forms of treatment. We compared data from the time period during which our study was conducted, which showed that about $32 \%$ of patients with complete cervical spine injuries would not survive 1 year postinjury and that about $5 \%$ could expect some degree of neurological improvement, with only $1 \%$ of patients with complete cervical SCIs recovering the ability to ambulate. ${ }^{43}$ In an effort to develop a predictive index for ambulatory outcomes after traumatic SCI, van Middendorp et al. found that having a complete spinal injury was itself associated with a negative predictive value of $92 \%$ with respect to being ambulatory at 1 year postinjury.$^{85}$ Review of data collected from the Model Spinal Cord Injury System ${ }^{58}$ found that there was a 3.5\% chance of status improving to ASIA Grade B and a $1.05 \%$ chance of improving to ASIA Grade C or D within 5 years of complete injury. An expert group reviewing data to provide information for the development of clinical trials on spinal cord injuries ${ }^{34}$ suggested a greater chance of functional improvement, concluding that $10 \%$ of patients with complete injury (ASIA Grade A) might convert to Grade B and $10 \%$ to Grade $\mathrm{C}$ within 1 year and less than $5 \%$ of patients with complete injury converting to ASIA Grade D. ${ }^{34}$ A larger proportion of the patients in our series achieved higher scores.

Of the 14 patients in our series with cervical SCIs, 4 (28.6\%) were self-sufficient after recovery and 1 (7\%) was able to ambulate. While data vary, more modern epidemiological studies have shown that, of persons with complete SCI, anywhere from $5 \%$ to $15 \%$ might expect to regain some degree of neurological function and from only $2 \%$ to $8 \%$ might expect to regain some degree of motor activity. ${ }^{58,69}$ Nine $(64 \%)$ of our patients with cervical spinal injuries recovered some sensory and motor function, and 3 (21\%) regained only some sensory function. Of particular interest is the patient in Case 4, who suffered a neurologically complete C-4 injury. According to data setting baseline expectations for Spinal Cord Independence measure III scores, ${ }^{16,54}$ persons with complete C-4 injury are unlikely to recover sufficient function to be functionally independent. ${ }^{2}$ The patient in Case 4 had such an injury and not only became independent but was also ambulatory following recovery. Data from a retrospective analysis ${ }^{48}$ indicate that about $3 \%-6 \%$ of persons with complete thoracic SCI might expect some degree of motor recovery. Three (50\%) of the 6 patients in our series with thoracic SCI regained some degree of motor control, including 1 who became ambulatory. In fact, 2 patients (10\%) in our series became ambulatory.

Respiratory problems were among the most common of the complications encountered in our series. This appears to be in concordance with literature on the subject:

TABLE 7: Improvement in motor and sensory scores*

\begin{tabular}{|c|c|c|c|c|c|c|c|c|c|c|}
\hline \multirow[b]{2}{*}{$\begin{array}{l}\text { Level of Spinal } \\
\text { Injury }\end{array}$} & \multicolumn{5}{|c|}{ Motor Index Scores } & \multicolumn{5}{|c|}{ Sensory Index Scores } \\
\hline & $\begin{array}{l}\text { Admission } \\
\text { (total) }\end{array}$ & $\begin{array}{l}\text { Admission } \\
\text { (mean) }\end{array}$ & FU (total) & FU (mean) & $\%$ Increase & $\begin{array}{l}\text { Admission } \\
\text { (total) }\end{array}$ & $\begin{array}{l}\text { Admission } \\
\text { (mean) }\end{array}$ & FU (total) & $\mathrm{FU}$ (mean) & $\%$ Increase \\
\hline cervical & 116 & 8.3 & 318 & 22.6 & 174 & 500 & 35.7 & 1336 & 95.4 & 167 \\
\hline thoracic & 300 & 50 & 363 & 60.5 & 21 & 696 & 116 & 916 & 152.7 & 32 \\
\hline all & 416 & 20.8 & 680 & 34 & 63 & 1196 & 59.8 & 2252 & 112.6 & 88 \\
\hline
\end{tabular}

* FU = follow-up. 


\section{R. R. Hansebout and C. R. Hansebout}

a 1994 study compiling 5 years of data found that $67 \%$ of acutely injured patients suffered some type of respiratory complication, namely atelectasis, pneumonia, or ventilatory failure..$^{55}$ It has also been added that such injuries were more common with a more rostral spinal cord injury or more severe injury, an assessment verified in later literature. ${ }^{3}$ Decubitus ulceration unfortunately occurred in our series of patients. This might have been prevented in a setting where the patient is placed on a pressure-reduction mattress or routinely turned onto each side at least every 2 hours. ${ }^{24}$ Urinary tract complications were also very common, although intermittent catheterization was used throughout treatment. Such infections are frequent in patients with SCI. ${ }^{25}$ Other complications include gastrointestinal hemorrhage and vertebral instability.

At present, opinion on the use of glucocorticoids after SCI is divided, ${ }^{32,50,72,79}$ largely as a result of criticisms of the trials ${ }^{17,19-22}$ designed to examine their efficacy. In the years during which this series' patients were treated, glucocorticoids were considered a de facto standard of care ${ }^{83}$ Given our personal experimental experience documenting the effects of these drugs, we felt they would be beneficial. One particular concern regarding their use is the risk of gastrointestinal bleeding, ${ }^{87}$ particularly given its intrinsic risk in spine-injured patients ${ }^{80}$ and epidemiological evidence associating steroids with gastrointestinal bleeding. ${ }^{39,49}$ In our series, 4 patients did experience gastrointestinal bleeding. One wonders whether this complication would have been as frequent had treatment taken place with modern stress ulcer prophylaxis.

The role of spinal cord decompression has also been questioned over the years. ${ }^{9}$ It is true that 5 of our patients were affected by some degree of orthopedic spinal instability after the initial operation, sometimes necessitating reexploration and fusion; while this is a recognized complication of the decompressive surgery, ${ }^{29}$ it is of concern. Many researchers believe that immediate decompressive treatment after a severe SCI is indicated. There are clinicians who feel that the results of decompression are no better with early decompression (within 24 hours of injury) than with decompression days later. ${ }^{1}$ One review, however ${ }^{35}$ showed that reduction of spinal fractures within 6 hours of injury allowed for the greatest degree of recovery. Other investigators ${ }^{63}$ have found that $26 \%$ of patients whose cord compression was reduced in the first 12 hours improved at least 2 grades on the Frankel Scale, while only $8 \%$ improved if the decompression was completed 12 hours following injury. Even late decompression may benefit some patients, suggesting that cord compression is an important component of neurological dysfunction. ${ }^{42}$ Newer data seem to agree that early, carefully performed decompression is indicated, ${ }^{36,38}$ particularly in situations where it can be performed soon after injury or in the presence of progressive neurological decline. There is still need for high-quality trials to examine the role of decompressive surgery in other, less obvious circumstances. ${ }^{11}$

The final constituent of our treatment regimen was cooling. There has, over the years, been modest interest in therapeutic hypothermia for traumatic $\mathrm{SCI},{ }^{27}$ with interest more recently focusing on systemic cooling. ${ }^{12,26}$ Hypothermia has been shown to have beneficial effects in trauma as diverse as reducing tissue metabolic demand, decreasing hemorrhage and edema formation, moderating apoptosis and excitotoxicity, reducing glial cell activation, decreasing the strength of the inflammatory response, and preserving blood vessel and blood-brain barrier structure. ${ }^{53,62}$ Much modern research focuses on the therapeutic potential of mild systemic hypothermia (that is, a body temperature of $32^{\circ}-35^{\circ} \mathrm{C}$ ). One particular technique, by which the body is cooled using closed-loop intravenous heat exchange, has been shown to be safe in a retrospective analysis ${ }^{28,64,65}$ and to yield promising results in a case-control study. ${ }^{26}$ By contrast, the technique used in the present series was regional hypothermia. Local cooling was initially valued because it avoided many of the potential complications of systemic hypothermia, notably arrhythmias, as well as potential long-term neurological deficits, which perhaps result from deranged cerebral blood flow regulation. ${ }^{10}$ In some circumstances, deeper cooling has been shown to be more effective than milder hypothermia. ${ }^{40,68,71}$ The ability to selectively deeply cool injured tissue while leaving core body temperature normal seems intuitively beneficial. Several series of cases ${ }^{47}$ seemed to indicate that regional hypothermia could be of great benefit. Regional cooling for the injured spinal cord, however, had fallen out of favor before high-quality controlled trials of its efficacy were conducted largely, it appears, because of criticisms of the requirement of a laminectomy, which might decrease spinal stability, and because of the supposedly lengthy period of time necessary to perform the procedure before cooling could be initiated. It is worth noting that, even if current expert opinion on decompression and fixation after acute $\mathrm{SCI}^{38}-$ that is, that surgical intervention should take place without delay-were proven to be incorrect, a subset of patients, presumably those with significant cord compression and neurological deficits or progressive neurological deterioration, ${ }^{44}$ will require decompression regardless of whether cooling is instituted. Recent studies ${ }^{73,81}$ have suggested that it may be possible to perform local cooling without surgery. Even assuming that dural exposure is necessary, as it was in our patients, the average time to cooling in our series was about 7.1 hours after injury. Given that cooling was applied locally, the temperature in the area of interest decreased very rapidly to the target level, likely within 5 minutes according to our studies in animals. ${ }^{78}$ After a severe SCI, swelling increases for 3 to 5 days and then begins to recede ${ }^{67}$ After only several hours of local profound cord cooling to a central cord temperature of about $17^{\circ} \mathrm{C}$, the cord appeared to be less tight beneath the dura (compare Figs. 4 and 5). This effect had not been observed after early decompression and steroid administration. This may indicate that low cord temperatures reduce posttraumatic cord swelling when hypothermia is initiated early. As a final note, after 1 patient with an incomplete severe cord lesion received local dural cooling at $6^{\circ} \mathrm{C}$, he went on to have a remarkable recovery. These findings show that the procedure is unlikely to cause obvious harm. Therefore, sustained levels of deep regional hypothermia can be safely achieved by means of our epidural technique of heat exchange.

Given that an optimal neuroprotective temperature in traumatic SCI has not yet been established, we suggest the pursuit of a method that allows the safe and efficacious 
lowering of temperature in a targeted area of the body, particularly in cases in which decompressive surgery is indicated. One drawback of the current technique, and thus an area for potential improvement, is that we are unable to apply cooling directly after an SCI has been sustained. Should the injured tissue be rendered hypothermic at this early stage, substantial autodestructive, secondary damage might be prevented. A method by which the spinal cord can be locally cooled to the desired temperature outside of hospitals would be of great value. One experimental study in rats has described a transcutaneous cooling mechanism able to decrease paraspinal temperature to $28.5^{\circ} \mathrm{C}$ and maintain this temperature for 1 hour. ${ }^{74}$ With further development, such a device might prove useful in beginning the process of targeted hypothermia to treat acute injury. Alternatively, methods could be developed to apply mild systemic hypothermia during patient transport as a prelude to the application of deep local hypothermia in hospital.

Because the current study is a case series, direct conclusions regarding the effectiveness of treatment cannot be drawn. We have presented the results of our small patient population in comparison with populations of patients with complete SCI receiving standard-of-care treatment. We admit that this is not an ideal control, but it does, we believe, allow some insight into how the average spinal cord-injured patient might be expected to recover. Since, in large series, patients with neurologically complete SCI experience very little return of motor function, we believe that the results in our patients stand in sharp contrast to those reported in large series; furthermore, given the positive outcome enjoyed by a substantial number of our patients, it may be inferred that our treatment regimen could be beneficial. Another limitation is that our treatment encompassed multiple modalities, and so the effect of any one of them singly cannot be assessed. Given that this experimental treatment occurred in the context of a series of cases, rather than a clinical trial, it was not considered ethically appropriate to provide patients with less than what was, at the time, considered to be the best possible care-namely, local decompression and systemic glucocorticoid therapy. In our prior and extensive experiments testing steroids and local cooling in spine-injured dogs, animals receiving both steroid therapy and cooling fared statistically significantly better than untreated controls. The addition of cooling in the present series was grounded in our previous experimental experience and offered to patients who had little hope of recovery with standard treatment.

\section{Conclusions}

We have presented the results obtained in 20 patients who presented with neurologically complete SCI and were treated with a combination of surgical decompression, glucocorticoid administration, and regional hypothermia. Our patients had better recoveries than might have been expected in patients undergoing traditional forms of treatment. The benefit of steroid treatment in SCI has been debated in the last decade, but we feel that research into the effects of cord cooling should be expanded. Given that the optimal neuroprotective temperature after acute trauma has not yet been defined, and may well be below that which is considered safely approachable through systemic cooling, methods that allow for the early attainment of such a temperature locally should be further explored. Our results are encouraging enough to suggest controlled clinical trials in which localized cooling of the spinal cord is applied when such treatment can be instituted within hours of injury.

\section{Disclosure}

The authors report no conflict of interest concerning the materials or methods used in this study or the findings specified in this paper.

Dr. R. R. Hansebout was supported by the Medical Research Council of Canada, Division of Mechanical Engineering (grant no. MA-3988), for basic research and the National Research Council of Canada, where the cooling equipment was built and maintained.

Author contributions to the study and manuscript preparation include the following. Conception and design: RR Hansebout. Acquisition of data: RR Hansebout. Analysis and interpretation of data: both authors. Drafting the article: both authors. Critically revising the article: both authors. Reviewed submitted version of manuscript: both authors. Approved the final version of the manuscript on behalf of both authors: RR Hansebout. Administrative/ technical/material support: RR Hansebout. Study supervision: RR Hansebout. Performed all surgeries and all neurological examinations: RR Hansebout.

\section{References}

1. Aebi M, Mohler J, Zäch GA, Morscher E: Indication, surgical technique, and results of 100 surgically-treated fractures and fracture-dislocations of the cervical spine. Clin Orthop Relat Res (203):244-257, 1986

2. Aidinoff E, Front L, Itzkovich M, Bluvshtein V, Gelernter I, Hart J, et al: Expected spinal cord independence measure, third version, scores for various neurological levels after complete spinal cord lesions. Spinal Cord 49:893-896, 2011

3. Aito S: Complications during the acute phase of traumatic spinal cord lesions. Spinal Cord 41:629-635, 2003

4. Albin MS, White RJ, Acosta-Rua G, Yashon D: Study of functional recovery produced by delayed localized cooling after spinal cord injury in primates. J Neurosurg 29:113-120, 1968

5. Albin MS, White RJ, Locke GS, Massopust LC Jr, Kretchmer HE: Localized spinal cord hypothermia-anesthetic effects and application to spinal cord injury. Anesth Analg 46:8-16, 1967

6. Albin MS, White RJ, MacCarty CS: Effects of sustained perfusion cooling of the subarachnoid space. Anesthesiology 24:72-80, 1963

7. Albin MS, White RJ, Yashon D, Harris LS: Effects of localized cooling on spinal cord trauma. J Trauma 9:1000-1008, 1969

8. Allen AR: Surgery of experimental lesion of spinal cord equivalent to crush injury of fracture dislocation of spinal column: a preliminary report. JAMA 57:878-880, 1911

9. Amar AP, Levy ML: Surgical controversies in the management of spinal cord injury. J Am Coll Surg 188:550-566, 1999

10. Arrica M, Bissonnette B: Therapeutic hypothermia. Semin Cardiothorac Vasc Anesth 11:6-15, 2007

11. Bagnall AM, Jones L, Duffy S, Riemsma RP: Spinal fixation surgery for acute traumatic spinal cord injury. Cochrane Database Syst Rev (1):CD004725, 2008

12. Batchelor PE, Skeers P, Antonic A, Wills TE, Howells DW, Macleod MR, et al: Systematic review and meta-analysis of therapeutic hypothermia in animal models of spinal cord injury. PLoS ONE 8:e71317, 2013

13. Black P: Recovery of spinal cord trauma: comparison of hypothermia and normothermic perfusion with and without durotomy. Congress of Neurological Surgeons Annual Meeting Proceedings, New Orleans, LA, 1976 (Abstract) 
14. Black P, Markowitz RS: Experimental spinal cord injury in monkeys: comparison of steroids and local hypothermia. Surg Forum 22:409-411, 1971

15. Black P, Shepard RH Jr, Markowitz RS: Spinal cord injury in monkey: comparison of normothermic and hypothermic perfusion. Congress of Neurological Surgeons Annual Meeting Proceedings, Atlanta, GA, 1975

16. Bluvshtein V, Front L, Itzkovich M, Aidinoff E, Gelernter I, Hart $\mathrm{J}$, et al: SCIM III is reliable and valid in a separate analysis for traumatic spinal cord lesions. Spinal Cord 49:292-296, 2011

17. Bracken MB: Steroids for acute spinal cord injury. Cochrane Database Syst Rev (3):CD001046, 2002

18. Bracken MB: Steroids for acute spinal cord injury. Cochrane Database Syst Rev 1:CD001046, 2012

19. Bracken MB, Shepard MJ, Collins WF Jr, Holford TR, Baskin DS, Eisenberg HM, et al: Methylprednisolone or naloxone treatment after acute spinal cord injury: 1-year follow-up data. Results of the second National Acute Spinal Cord Injury Study. J Neurosurg 76:23-31, 1992

20. Bracken MB, Shepard MJ, Collins WF, Holford TR, Young W, Baskin DS, et al: A randomized, controlled trial of methylprednisolone or naloxone in the treatment of acute spinal-cord injury. Results of the Second National Acute Spinal Cord Injury Study. N Engl J Med 322:1405-1411, 1990

21. Bracken MB, Shepard MJ, Hellenbrand KG, Collins WF, Leo LS, Freeman DF, et al: Methylprednisolone and neurological function 1 year after spinal cord injury. Results of the National Acute Spinal Cord Injury Study. J Neurosurg 63:704-713, 1985

22. Bracken MB, Shepard MJ, Holford TR, Leo-Summers L, Aldrich EF, Fazl M, et al: Administration of methylprednisolone for 24 or 48 hours or tirilazad mesylate for 48 hours in the treatment of acute spinal cord injury. Results of the Third National Acute Spinal Cord Injury Randomized Controlled Trial. JAMA 277:1597-1604, 1997

23. Campbell JB, DeCrescito V, Tomasula JJ, Demopoulos HB, Flamm ES, Ransohoff J: Experimental treatment of spinal cord contusion in the cat. Surg Neurol 1:102-106, 1973

24. Consortium for Spinal Cord Medicine: Early acute management in adults with spinal cord injury: a clinical practice guideline for health-care professionals. J Spinal Cord Med 31:403-479, 2008

25. D'Hondt F, Everaert K: Urinary tract infections in patients with spinal cord injuries. Curr Infect Dis Rep 13:544-551, 2011

26. Dididze M, Green BA, Dalton Dietrich W, Vanni S, Wang MY, Levi AD: Systemic hypothermia in acute cervical spinal cord injury: a case-controlled study. Spinal Cord 51:395-400, 2013

27. Dietrich WD III: Therapeutic hypothermia for spinal cord injury. Crit Care Med 37 (7 Suppl):S238-S242, 2009

28. Dietrich WD, Levi AD, Wang M, Green BA: Hypothermic treatment for acute spinal cord injury. Neurotherapeutics 8: 229-239, 2011

29. Dimar JR, Fisher C, Vaccaro AR, Okonkwo DO, Dvorak M, Fehlings M, et al: Predictors of complications after spinal stabilization of thoracolumbar spine injuries. J Trauma 69: 1497-1500, 2010

30. Ditunno JF, Little JW, Tessler A, Burns AS: Spinal shock revisited: a four-phase model. Spinal Cord 42:383-395, 2004

31. Ducker TB, Hamit HF: Experimental treatments of acute spinal cord injury. J Neurosurg 30:693-697, 1969

32. Eck JC, Nachtigall D, Humphreys SC, Hodges SD: Questionnaire survey of spine surgeons on the use of methylprednisolone for acute spinal cord injury. Spine (Phila Pa 1976) 31:E250-E253, 2006

33. Eidelberg E, Staten E, Watkins CJ, Smith JS: Treatment of experimental spinal cord injury in ferrets. Surg Neurol 6:243246, 1976

34. Fawcett JW, Curt A, Steeves JD, Coleman WP, Tuszynski $\mathrm{MH}$, Lammertse D, et al: Guidelines for the conduct of clini- cal trials for spinal cord injury as developed by the ICCP panel: spontaneous recovery after spinal cord injury and statistical power needed for therapeutic clinical trials. Spinal Cord 45:190-205, 2007

35. Fehlings MG, Perrin RG: The role and timing of early decompression for cervical spinal cord injury: update with a review of recent clinical evidence. Injury 36 (Suppl 2):B13-B26, 2005

36. Fehlings MG, Perrin RG: The timing of surgical intervention in the treatment of spinal cord injury: a systematic review of recent clinical evidence. Spine (Phila Pa 1976) 31 (11 Suppl): S28-S36, 2006

37. Fisher CG, Noonan VK, Smith DE, Wing PC, Dvorak MF, Kwon BK: Motor recovery, functional status, and health-related quality of life in patients with complete spinal cord injuries. Spine (Phila Pa 1976) 30:2200-2207, 2005

38. Furlan JC, Noonan V, Cadotte DW, Fehlings MG: Timing of decompressive surgery of spinal cord after traumatic spinal cord injury: an evidence-based examination of pre-clinical and clinical studies. J Neurotrauma 28:1371-1399, 2011

39. Garcia Rodríguez LA, Hernández-Díaz S: The risk of upper gastrointestinal complications associated with nonsteroidal anti-inflammatory drugs, glucocorticoids, acetaminophen, and combinations of these agents. Arthritis Res 3:98-101, 2001

40. Gillinov AM, Redmond JM, Zehr KJ, Troncoso JC, Arroyo S, Lesser RP, et al: Superior cerebral protection with profound hypothermia during circulatory arrest. Ann Thorac Surg 55: 1432-1439, 1993

41. Green BA, Kahn T, Klose KJ: A comparative study of steroid therapy in acute experimental spinal cord injury. Surg Neurol 13:91-97, 1980

42. Hadley MN: Initial closed reduction of cervical spine fracturedislocation injuries. Neurosurgery 50 (3 Suppl):S44-S50, 2002

43. Hansebout RR: A comprehensive review of methods of improving cord recovery after acute spinal cord injury, in Tator $\mathrm{CH}$ (ed): Early Management of Acute Spinal Cord Injury. Seminars in Neurological Surgery Series. New York: Raven Press, 1982, pp 181-196

44. Hansebout RR, Kachur E: Acute traumatic spinal cord injury. UpToDate. (http://www.uptodate.com/contents/acute-trauma tic-spinal-cord-injury) [Accessed February 5, 2014]

45. Hansebout RR, Kuchner EF, Romero-Sierra C: Effects of local hypothermia and of steroids upon recovery from experimental spinal cord compression injury. Surg Neurol 4:531-536, 1975

46. Hansebout RR, Lewin MG, Pappius HM: Evidence regarding the action of steroids in injured spinal cord, in Reulen HG, Schürmann K (eds): Steroids and Brain Edema. Berlin: Springer-Verlag, 1972, pp 153-155

47. Hansebout RR, Tanner JA, Romero-Sierra C: Current status of spinal cord cooling in the treatment of acute spinal cord injury. Spine (Phila Pa 1976) 9:508-511, 1984

48. Harrop JS, Naroji S, Maltenfort MG, Ratliff JK, Tjoumakaris SI, Frank B, et al: Neurologic improvement after thoracic, thoracolumbar, and lumbar spinal cord (conus medullaris) injuries. Spine (Phila Pa 1976) 36:21-25, 2011

49. Hernández-Díaz S, Rodríguez LA: Steroids and risk of upper gastrointestinal complications. Am J Epidemiol 153:10891093, 2001

50. Hugenholtz H, Cass DE, Dvorak MF, Fewer DH, Fox RJ, Izukawa DM, et al: High-dose methylprednisolone for acute closed spinal cord injury-only a treatment option. Can J Neurol Sci 29:227-235, 2002

51. Hurlbert RJ: The role of steroids in acute spinal cord injury: an evidence-based analysis. Spine (Phila Pa 1976) 26 (24 Suppl): S39-S46, 2001

52. Hurlbert RJ, Moulton R: Why do you prescribe methylprednisolone for acute spinal cord injury? A Canadian perspective and a position statement. Can J Neurol Sci 29:236-239, 2002

53. Inamasu J, Nakamura Y, Ichikizaki K: Induced hypothermia 
in experimental traumatic spinal cord injury: an update. J Neurol Sci 209:55-60, 2003

54. Itzkovich M, Gelernter I, Biering-Sorensen F, Weeks C, Laramee MT, Craven BC, et al: The Spinal Cord Independence Measure (SCIM) version III: reliability and validity in a multicenter international study. Disabil Rehabil 29:1926-1933, 2007

55. Jackson AB, Groomes TE: Incidence of respiratory complications following spinal cord injury. Arch Phys Med Rehabil 75:270-275, 1994

56. Janssen L, Hansebout RR: Pathogenesis of spinal cord injury and newer treatments. A review. Spine (Phila Pa 1976) 14: 23-32, 1989

57. Kelly DL Jr, Lassiter KR, Calogero JA, Alexander E Jr: Effects of local hypothermia and tissue oxygen studies in experimental paraplegia. J Neurosurg 33:554-563, 1970

58. Kirshblum S, Millis S, McKinley W, Tulsky D: Late neurologic recovery after traumatic spinal cord injury. Arch Phys Med Rehabil 85:1811-1817, 2004

59. Kirshblum SC, Burns SP, Biering-Sorensen F, Donovan W, Graves DE, Jha A, et al: International standards for neurological classification of spinal cord injury (revised 2011). J Spinal Cord Med 34:535-546, 2011

60. Kuchner EF, Hansebout RR: Combined steroid and hypothermia treatment of experimental spinal cord injury. Surg Neurol 6:371-376, 1976

61. Kuchner EF, Mercer ID, Pappius HM, Hansebout RR: Experimental spinal cord injury: effects of steroids and/or cooling on edema, electrolytes, and motor recovery, in Pappius HM, Feindel WF (eds): Dynamics of Brain Edema: Proceedings of the Third International Workshop on Dynamic Aspects of Cerebral Edema, Montreal, Canada, June 25-29, 1976. Berlin: Springer-Verlag, 1976, pp 315-322

62. Kwon BK, Mann C, Sohn HM, Hilibrand AS, Phillips FM, Wang JC, et al: Hypothermia for spinal cord injury. Spine J 8:859-874, 2008

63. Lee AS, MacLean JC, Newton DA: Rapid traction for reduction of cervical spine dislocations. J Bone Joint Surg Br 76: 352-356, 1994

64. Levi AD, Casella G, Green BA, Dietrich WD, Vanni S, Jagid J, et al: Clinical outcomes using modest intravascular hypothermia after acute cervical spinal cord injury. Neurosurgery 66:670-677, 2010

65. Levi AD, Green BA, Wang MY, Dietrich WD, Brindle T, Vanni S, et al: Clinical application of modest hypothermia after spinal cord injury. J Neurotrauma 26:407-415, 2009

66. Lewin MG, Hansebout RR, Pappius HM: Chemical characteristics of traumatic spinal cord edema in cats. Effects of steroids on potassium depletion. J Neurosurg 40:65-75, 1974

67. Lewin MG, Pappius HM, Hansebout RR: Effects of steroids on edema associated with injuries of the spinal cord, in Reulen HG, Schürmann K: Steroids and Brain Edema. Berlin: Springer-Verlag, 1972, pp 101-112

68. Lima B, Williams JB, Bhattacharya SD, Shah AA, Andersen $\mathrm{N}$, Gaca JG, et al: Results of proximal arch replacement using deep hypothermia for circulatory arrest: is moderate hypothermia really justifiable? Am Surg 77:1438-1444, 2011

69. Marino RJ, Burns S, Graves DE, Leiby BE, Kirshblum S, Lammertse DP: Upper- and lower-extremity motor recovery after traumatic cervical spinal cord injury: an update from the national spinal cord injury database. Arch Phys Med Rehabil 92:369-375, 2011

70. McDonald JW, Becker D, Sadowsky CL, Jane JAS Sr, Conturo TE, Schultz LM: Late recovery following spinal cord injury. Case report and review of the literature. J Neurosurg 97 (2 Suppl):252-265, 2002 [Erratum in J Neurosurg 97 (3 Suppl): 405-406, 2002]
71. Mezrow CK, Midulla PS, Sadeghi AM, Gandsas A, Wang W, Dapunt OE, et al: Evaluation of cerebral metabolism and quantitative electroencephalography after hypothermic circulatory arrest and low-flow cardiopulmonary bypass at different temperatures. J Thorac Cardiovasc Surg 107:1006-1019, 1994

72. Miller SM: Methylprednisolone in acute spinal cord injury: a tarnished standard. J Neurosurg Anesthesiol 20:140-142, 2008

73. Morizane K, Ogata T, Morino T, Horiuchi H, Yamaoka G, Hino $\mathrm{M}$, et al: A novel thermoelectric cooling device using Peltier modules for inducing local hypothermia of the spinal cord: the effect of local electrically controlled cooling for the treatment of spinal cord injuries in conscious rats. Neurosci Res 72:279282, 2012

74. Morochovic R, Chudá M, Talánová J, Cibur P, Kitka M, Vanický I: Local transcutaneous cooling of the spinal cord in the rat: effects on long-term outcomes after compression spinal cord injury. Int J Neurosci 118:555-568, 2008

75. Negrin J Jr: [Direct regional hypothermia of the brain by extravascular intracranial perfusion.] Rev Neurol (Paris) 108: 923-927, 1963 (Fr)

76. Negrin J Jr: Prévention des lésions de la moelle épiniére par l'hypothermia régionale extravasculaire. Rev Neurol (Paris) 106: $725-729,1962$

77. Oyinbo CA: Secondary injury mechanisms in traumatic spinal cord injury: a nugget of this multiply cascade. Acta Neurobiol Exp (Warsz) 71:281-299, 2011

78. Romero-Sierra C, Hansebout R, Sierhuis A, Lewin M: A new method for localised spinal-cord cooling. Med Biol Eng 12:188-193, 1974

79. Rozet I: Methylprednisolone in acute spinal cord injury: is there any other ethical choice? J Neurosurg Anesthesiol 20: 137-139, 2008

80. Simons RK, Hoyt DB, Winchell RJ, Holbrook T, Eastman AB: A risk analysis of stress ulceration after trauma. J Trauma 39:289-294, 1995

81. Smith KD, Zhu L: Theoretical evaluation of a simple cooling pad for inducing hypothermia in the spinal cord following traumatic injury. Med Biol Eng Comput 48:167-175, 2010

82. Tator $\mathrm{CH}$, Fehlings MG: Review of the secondary injury theory of acute spinal cord trauma with emphasis on vascular mechanisms. J Neurosurg 75:15-26, 1991

83. Tator CH, Rowed DW: Current concepts in the immediate management of acute spinal cord injuries. Can Med Assoc J 121:1453-1464, 1979

84. Thienprasit P, Bantli H, Bloedel JR, Chou SN: Effect of delayed local cooling on experimental spinal cord injury. J Neurosurg 42:150-154, 1975

85. van Middendorp JJ, Hosman AJ, Donders AR, Pouw MH, Ditunno JF Jr, Curt A, et al: A clinical prediction rule for ambulation outcomes after traumatic spinal cord injury: a longitudinal cohort study. Lancet 377:1004-1010, 2011

86. Wells JD, Hansebout RR: Local hypothermia in experimental spinal cord trauma. Surg Neurol 10:200-204, 1978

87. Wuermser LA, Ho CH, Chiodo AE, Priebe MM, Kirshblum SC, Scelza WM: Spinal cord injury medicine. 2. Acute care management of traumatic and nontraumatic injury. Arch Phys Med Rehabil 88 (3 Suppl 1):S55-S61, 2007

Manuscript submitted April 1, 2013.

Accepted February 4, 2014.

Please include this information when citing this paper: published online March 14, 2014; DOI: 10.3171/2014.2.SPINE13318.

Address correspondence to: Robert R. Hansebout, M.D., M.Sc., 589 Scenic Dr.,Hamilton, ON, Canada L9C 1H1. email: hansebou@ mcmaster.ca. 